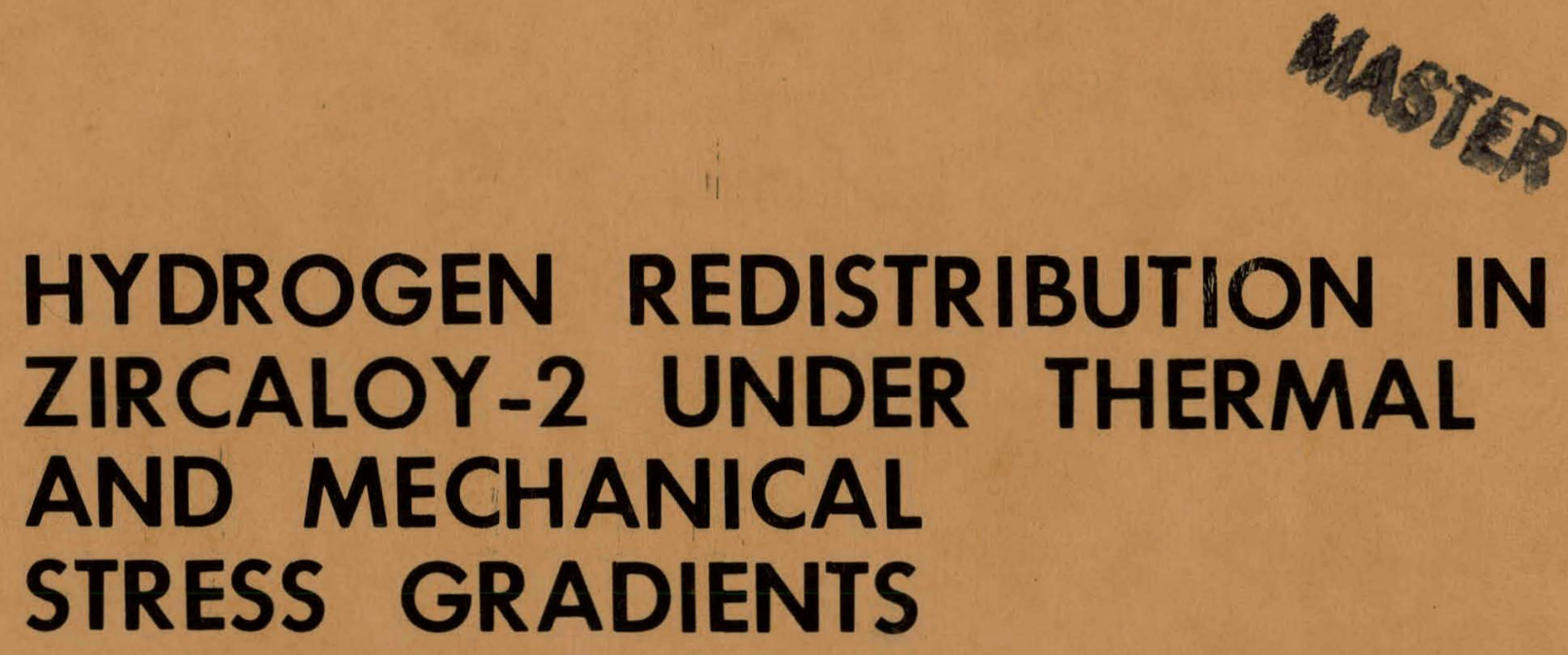

January 1959

Contract AT-11-1-GEN-14

BETTIS PLANT-PITTSBURGH, PA. OPERATED FOR THE U.S. ATOMIC ENERGY COMMISSION BY BETTIS ATOMIC POWER DIVISION, WESTINGHOUSE ELECTRIC CORPORATION

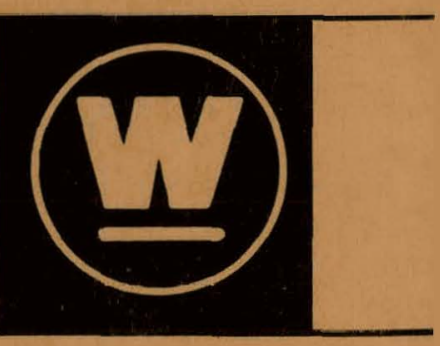




\section{DISCLAIMER}

This report was prepared as an account of work sponsored by an agency of the United States Government. Neither the United States Government nor any agency Thereof, nor any of their employees, makes any warranty, express or implied, or assumes any legal liability or responsibility for the accuracy, completeness, or usefulness of any information, apparatus, product, or process disclosed, or represents that its use would not infringe privately owned rights. Reference herein to any specific commercial product, process, or service by trade name, trademark, manufacturer, or otherwise does not necessarily constitute or imply its endorsement, recommendation, or favoring by the United States Government or any agency thereof. The views and opinions of authors expressed herein do not necessarily state or reflect those of the United States Government or any agency thereof. 


\section{DISCLAIMER}

Portions of this document may be illegible in electronic image products. Images are produced from the best available original document. 
UC-25: Metallurgy and Ceramics

\title{
HYDROGEN REDISTRIBUTION IN ZIRCALOY-2 UNDER THERMAL AND MECHANICAL STRESS GRADIENTS
}

J. M. Markowitz

Contract AT-11-1-GEN-14

January 1959

Price $\$ .75$

Available from the Office of Technical Services,

Department of Commerce,

Washington 25, D. C.

This document is an interim memorandum prepared primarily for internal reference and does not represent a final expression of the opinion of Westinghouse. When this memorandum is distributed externally, it is with the express understanding that Westinghouse makes no representation as to completeness, accuracy, or usability of information contained therein.

\author{
BETTIS PLANT - PITTSBURGH, PA. \\ OPERATED FOR THE U.S. ATOMIC ENERGY COMMISSION BY \\ BETTIS ATOMIC POWER DIVISION, WESTINGHOUSE ELECTRIC CORPORATION
}


UC:-25: Mețallurgy and Ceramics, TID $-4500,14$ th Edition $5660 \% \because 3$

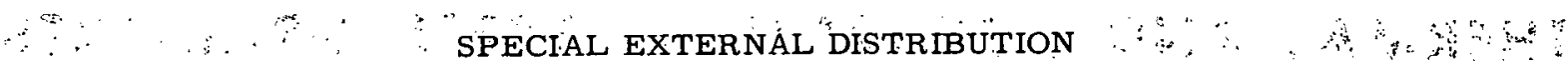
Manager, Hittsburgh Naval Keactors Uperations Üfice

Thio roport wao propared äg an aceount of oovernment sponsuited ivilk. Neither the United States Navy, nor the Commission, nor any person acting on behalf oft the Comimission:

A. Makes any warranty or representation, express or implied, with respect to the accuracy, completeness, or usefulness of the information contained in this report, or that the use: of any information, apparatus, method, or process disclosed in this report may not infringe privately owned rights; or

B. Assumes any liabilities with respect to the use of, or for damages resulting from the use of any information, apparatus, method, or process disclosed in this report.

As used in the above, "persons acting on behalf of the commission" includes any employe or contractor of the commission to the extent that such employe or contractor "prepares, "handles or distributes, or provides access.to, -anyInformation purouant to hlo omploymont or contraet with the U. S. Navy or the Commission. 
TABLE OF CONTENTS

Page No.

INTRODUCTION
EXPERIMENTAL
DATA AND RESULTS
Thermal Diffusion
Stress Gradient Diffusion
Activity Gradient Studies
DISCUSSION
Effect of Stress
Activity Gradient on the $\alpha-\delta$ Region
Kinetics
Vapor-Phase Transport
Thermal Conductivity
FUTURE WORK
REFERENCES
TABLES
FIGURES
APPENDIX


Past and current work on the study of the movement of dissolved hydrogen in Zircaloy-2 under the influence of thermal, mechanical stress and two-phase activity gradients is reviewed, and the findings are discussed. A program of future work is presented.

\section{HYDROGEN REDISTRIBUTION IN ZIRCALOY -2 \\ UNDER THERMAL AND MECHANICAL STRESS GRADIENTS}

J. M. Markowitz

\section{INTRODUCTION}

This report covers progress from January, 1958, to the present. Earlier reports covered the original work on hydrogen redistribution under thermal gradients and the consequences of thermal redistribution in terms of estimated cladding lifetimes in service (Refs 1 and 2). But since that time, new experimental information has been obtained about the magnitude of the thermal diffusion effect. It is recognized also that mechanical stress gradients must play an important role in the redistribution phenomenon. The available experimental information on hydrogen redistribution in pure tensile, pure compressive, and mixed mechanical gradients under isothermal conditions will therefore also be discussed.

\section{EXPERIMENTAL}

Experimental methods in the temperature gradient diffusion work have been covered in the earlier reports (Refs 1 and 2). Briefly, a cylindrical specimen of 2 -in. diameter and 6-in. length, with a 1/4-in. axial hole, is annealed in a hydrogen atmosphere until sufficient hydrogen gas has dissolved to provide the desired concentration. The specimen is then placed in a second annealing furnace having an atmosphere of purified argon and is provided with an axial flow of cooling water, either in direct contact with the Zircaloy or passing through a copper tube which is itself in direct contact. Subsequent to this anneal, a circular section from near the axial center of the specimen is cut into samples for analysis.

Tensile gradient specimens are cylinders 5 1/2-in. long, threaded at both ends for chucking in the test machine. The end diameters are 0.635 in., but $11 / 4$-in. from either end, the cylinder tapers to a 1/2-in. long center section 0.320 in. in diameter. The two tapered sections represent the region of stress gradient under test, the stress ratio being about 4:1. Testing is performed in a Curnace under an argon atmosphere and at the desired static load. Specimen dimensions are accurately measured in an optical comparator before and after test. 
The original compression test specimens were similar in form to the tensile test specimens, $51 / 2$-in. long with a 0.626 end diam. and a 0.286 center diameter; the ends were, of course, not threaded. The compression apparatus consists of a pair of heat-treated dies, the lower fixed into a steel support plate and the upper, with a hemispherical top, being fixed in position by passing through an accurately located hole in a circular table; this table is supported and fixed in position by the steel furnace tube which surrounds the dies concentrically and is bolted to the lower plate: The load is applied to the upper die by loading a steel top plate, which rests on the hemispherical die top on a mating hardened steel cup, with lead bricks. The entire assembly is about 18 in. high. The specimen is placed vertically between the two dies, and a split furnace is placed around the furnace tube. Provision is made for introducing an argon atmosphere into the furnace tube.

In the first run in this apparatus, the specimen buckled at temperature, although the total load was such that the maximum stress was only a small fraction of the yield strength. However, by considering the compression specimen as a column and calculating the critical loading, it was found that the experimental load applied was about $70 \%$ of the critical load for buckling; at this load even a small eccentricity in loading could cause buckling. A second specimen of the same shape was subsequently run, taking extreme precautions to prevent eccentricity, and nu buckling occurred. However, to prevent recurrence, the specimens have been redesigned and given a barrel-shape, tapering from a thick center to narrow ends; this design is such that the same experimental load will be only $30 \%$ of critical.

One experiment has been performed in which a composite mechanical stress gradient was set up by the differential thermal expansion between a Zircaloy-2 annulus and a stainless steel axial plug. The annulus dimensions were $1.937 \times 0.4384$ in., and the O.D. of the stainless plug was $0.4381 \mathrm{in.}$ (The diametral dimensions are averages based on a number of micrometer measurements. Some chilling of the plug was necessary for smooth insertion.) The respective thermal expansions of plug and annulus were sufficient to create an internal pressure of considerable magnitude when the specimen was treated at $350^{\circ} \mathrm{C}$ in an argon atmosphere.

\section{DATA AND RESULTS}

\section{Thermal Diffusion}

Table I presents a summary of all experiments performed by annealing specimens in.a temperature gradient, including some experiments now in progress. Cunditions dre given for each experiment together with the calculated value of $Q *$, the heat of transport. The average of the reported values of $Q *$ is $3.5 \pm 1.5 \mathrm{kcal} / \mathrm{mole}$. No value of $Q *$ has been reported for specimen 2; part of this specimen was in the two-phase $\alpha-\delta$ region during the anneal, and the concentration vs reciprocal temperature line has too much curvature for a slope to be determined accurately. However, the mean slope (chosen arbitrarily) gives a value of about $4.5 \mathrm{kcal} / \mathrm{mole}$ for $Q *$.

In compiling these data, the chief uncertainty lay in the measurement of temperatures through the gradient. Theoretically, for a substance whose thermal conductivity is independent of temperature, the temperature in a cylindrical gradient is proportional to the logarithm of the radius. In the case of Zircaloy-2, for which the thermal conductivity follows the relation (Ref 3 )

$$
\mathrm{K}=\mathrm{A}(1+\mathrm{BT})
$$

in the temperature range of interest, the gradient of temperature is given by

$$
\mathrm{T}+(\mathrm{B} / 2) \mathrm{T}^{2}=\mathrm{m} \ln \mathrm{r}+\mathrm{n}
$$

where $m$ and $n$ are constants, and $A=0.116$ and $B=3.23 \times 10^{-4}$. Equation (2) was used to calculate curves of $\mathrm{T}$ vs $\mathrm{r}$ for the study being reported. 
In setting up the experimental apparatus, three to five thermocouples were positioned at different radial points. Their output was continuously recorded on a multipoint recorder, and the temperatures were calculated by averaging the chart records. In a number of the experiments, the measured temperatures were completely consistent, i.e., conformed to Eq (2). On the other hand, in experiments 4, 5, and 6, in each of which three thermocouples were used, this was not true. In order to fix the temperature gradient, it was therefore necessary to exercise judgment in drawing the best straight line on a plot of $\left[T+(B / 2) T^{2}\right]$ vs $\ln \cdot r$. The data given in Table I represent the results obtained by ignoring the inner thermocouple and using only the outer two to determine the gradient.

This procedure is justified by several considerations: It leads to a more consistent grouping of the data when plotted as logarithm of concentration vs reciprocal temperature; the data are much less scattered than if the inner thermocouple is considered in determining the gradient. Furthermore, there is some doubt of the uniformity of contact of the copper tubing used to convey cooling water along the specimen axis. Thus, if an angular temperature distribution exists from this cause, the innermost thermocouple would be most apt to give an inconsistent reading. Finally, the form and slope of the gradients calculated by the procedure described are in accord with those calculated for experiments in which all the temperatures were found consistent with Eq (2) (specifically, 2, 3, 7 and 9); on the other hand, if the measured inner temperature is taken into account in calculating the gradients, they appear much too steep.

A number of methods of insuring good thermal contact between copper-water tube and the specimen I.D. have been tried. It is hoped that the one being used with specimen 9 , in which the copper tube is mechanically swaged to the Zircaloy after insertion, will eliminate future temperature anomalies. It is possible that this method can be further improved by copper plating the specimen I.D. before the swaging procedure.

The accuracy of the analysis of Zircaloy -2 for hydrogen has given considerable concern as a cause of inconsistencies in the data. There is no doubt that refinement in the means of analysis would give much more trustworthy results. The evidence at present indicates that the precision of analysis at the $50 \mathrm{ppm}$ level is satisfactory and more than commensurate with the precision of the measurement of the temperature gradient. At higher concentration levels the precision of the results decreases ( $\pm 8 \mathrm{ppm}$ at $230 \mathrm{ppm}$ ) and cannot be considered fully satisfactory.

\section{Stress Gradient Diffusion}

As previously described, three types of experiments have been carried out to measure isothermal hydrogen redistribution in Zircaloy -2 under mechanical stress gradients. Twn experi.ments have been completed in a pure tensile gradient, one in a pure compressional gradient, and one in a composite cylindrical gradient. Others are now in progress. The experimental conditions are given in Table II, and the results are plotted in Fig. 1.

The two experiments on pure tensile gradient diffusion gave contrasting results. At $550^{\circ} \mathrm{C}$ and a relatively low stress gradient, considerable redistribution occurred in two weeks. Considerable permanent set was observed for this specimen after its removal from test. The specimen at $350^{\circ} \mathrm{C}$ was subjected to a considerably higher stress for an equal period of time, and, although some redistribution has prubably occurred, its extent is difficult to determine because of the scatter of the analytical data.

On the other hand, a compressional gradient specimen experienced hydrogen redistribution toward the region of maximum stress at approximately the same temperature as that of the second tensile gradient specimen after exposure for twice the time and under a considerably lighter load. The redistribution cxpcricnced was frum 84 lo $110 \mathrm{ppm}$ over a length of about 1.4 in. and over a 
stress difference of about $6000 \mathrm{psi}$, after $600 \mathrm{hr}$ at $360^{\circ} \mathrm{C}$ (see Table II and Fig. 1). The average concentration was $87 \mathrm{ppm}$. A second specimen, which was treated with the first during hydrogen dissolution and homogenization but was not subsequently heat treated in any way, was also analyzed. This specimen showed a distribution of hydrogen very like the analogous stress gradient specimen, running from 80 to $101 \mathrm{ppm}$ in $1.4 \mathrm{in.}$, and the average concentration was 81 ppm. This second specimen is not regarded as a true control (it was not treated at $360^{\circ} \mathrm{C}$ for $600 \mathrm{hr}$ at no load); it is felt that the similarity in hydrogen distribution is due to incomplete homogenization immediately after hydrogen dissolution. It is shown later that a $600 \mathrm{hr}$ treatment at $360^{\circ} \mathrm{C}$ should completely homogenize the concentration in a specimen of this size. To make absolutely certain of this, a complete control is being run in parallel with specimen 5-CG (Table I), including a noload heat treatment at the same temperature and for the same period of time. Reserving judgment on these points, the most appropriate conclusion from the data is that compressional stress gradients cause redistribution in the direction of increasing stress in a period of three weeks at $360^{\circ} \mathrm{C}$.

If the rate of redistribution in a tensile gradient is comparable with that in a compressional gradient. it would appear that a two-week exposure is too short at $350^{\circ} \mathrm{C}$, and that a more definite pattern of redistribution would be observable lin a leusile gradient apccimen exposed for a longer time or at a higher temperature. Currently, a tensile specimen is being treated at $400^{\circ} \mathrm{C}$ for two weeks in a stress gradient calculated to produce the same permanent set as the $350^{\circ} \mathrm{C}$ specimen. A second compressional gradient specimen of the barrel-shaped design is also being treated at $400^{\circ} \mathrm{C}$. Temperatures and times of exposure will be discussed later.

The composite stress gradient specimen was run at $350^{\circ} \mathrm{C}$ for about two weeks. A partial analysis performed on conclusion of the experiment showed the average concentration (four to six determinations) at each of five radial locations to lie within the range $53 \pm 3$ ppm, with no parlleular. trend of concentration variation. The variation of stress through the radius of this specimen is shown in Fig. 2. The radial and tangential stresses accompanying the differential fit process described in section II were first calculated on the basis of pure elastlc considerations. Curves for these stresses as well as for the maximum shearing stress (that existing on a plane inclined at $45^{\circ}$ to the radius) appear in Fig. 2. In order to determine the actual stresses, the maximum shear theory of strength was assumed. The $0.2 \%$ offset yield strength in torsion (Ref 3 ) was used as the shear yield point; it was assumed that this number varies with temperature in the same way as the corresponding yield point in tension, for which ternperature data are available. It was also assumed that, beyond the yield point, Zircaloy-2 yields without any further increase in shearing stress. In addition, the calculation neglects any changes in the elastic moduli with temperature. The new stress curves thus calculated show that plastic deformation occurs in a band of the specimen about $0.36 \mathrm{in}$. in diameter. Because of the assumptions used, the curves must be regarded as approximate.

According to these calculations, the total gradient of stress is $4500 \mathrm{psi} / \mathrm{cm}$ tangential, 4300 psi/cm radial, and about $4000 . p s i / c m$ shear. Further stress relaxation due to creep was calculated to be negligible. Since these values are all somewhat higher than those used in the linear gradient experiments (the maximum shear stress in a linear specimen is approximately one-half the tensile or compressive stress), some redistribution should have occurred. Therefore, this specimen is being reanalyzed, using a grid-type sampling technique, to see if an angular asymmetry in the redistribution caused the apparent negative result; also, further experiments of this type will be conducted, using a static internal stress rather than a differential stress.

\section{Activity Gradient Studies}

There have been two activity gradient studies. In the first, three wedges cut from a circular section of specimen 2 (see Table I) were sealed in evacuated bulbs and annealed for periods of 
two to four weeks at $360^{\circ} \mathrm{C}$. The fourth wedge was retained as a control. On completion of the annealing, all four wedges were cut up and analyzed. The results are shown in Fig. 3 . The insert. locates the range of composition involved on the phase diagram. The curve marked "original" represents smoothed data from the original analysis of specimen 2 . Wedges 2 and 3 were each annealed for four weeks, while wedge 1 was annealed for only two weeks. The concentration distribution for the latter is essentially the same as. that of the control within the limits of the analytical precision ( $\pm 8 \mathrm{ppm}$ ). The distributions in the four-week specimens (wedges 2 and 3 ) are shifted somewhat; wedge 2 appears to have increased its hydrogen content near the outside, and wedge 3 near the inside. These data do not indicate any large-scale redistribution at $360^{\circ} \mathrm{C}$ for four weeks. However, there is enough ambiguity in the data, particularly with wedge 3 , to warrant further experiments of this kind.

In the second type of activity gradient experiment, three $0.2-\mathrm{g}$ pieces of hydrogen-free Zircaloy-2 and a $60 \mathrm{~g}$ piece at a concentration of about $300 \mathrm{ppm}$ were annealed together in an evacuated bulb. The smaller pieces consisted of spent analytical samples, heated in the process of analysis for several hours in a high vacuum at $1200^{\circ} \mathrm{C}$. The $60-\mathrm{g}$ pieces were charged with hydrogen and annealed in the $\alpha$-region of the phase diagram; the subsequent bulb annealing was performed at a lower temperature to place the larger specimens in the two-phase region. Four separate runs were made: two weeks and five weeks at $360^{\circ} \mathrm{C}$, two weeks at $400^{\circ} \mathrm{C}$, and two weeks at $450^{\circ} \mathrm{C}$ (the latter was to be a control, both large and small specimens in the $\alpha$-region). Analyses of the smaller specimens subsequent to these runs gave the following hydrogen concentrations, respectively: $5 \pm 2$, $4 \pm 1,8 \pm 8$ and 0.0 (below the limit of resolution of the analytical apparatus). It is obvious that these results are anomalous; the expected concentration levels should be between 100 and 140 ppm.

It is possible that the low results are related to the character of the $0.2-\mathrm{g}$ specimens. As described above, they were spent analytical samples; they had rested in the graphite susceptor crucible of the induction heating apparatus for a number of hours at $1200^{\circ} \mathrm{C}$. Under these circumstances, even though in a reducing environment, there is some possibility of oxygen contamination or of surface changes unfavorable to the subsequent entry and dissolution of hydrogen (although the data of Mallett and Albrecht (Ref 5) show an actual increase of hydrogen solubility at low hydrogen pressures when the oxygen content is increased). To avoid the se possibilities in the future, $0.2-\mathrm{g}$ specimens will be cut from the $60 \mathrm{-g}$ specimens after extended outgassing at $550^{\circ} \mathrm{C}$. It is unlikely that the specimens will be completely hydrogen free, but the specimens should be homogeneous in oxygen content. Hydrogen will then be dissolved in the $60-\mathrm{g}$ specimens to the desired level. In addition, paired specimens having differing concentrations which place both in the two-phase region, will be annealed in vacuo to detect any redistribution which may occur.

\section{DISCUSSION}

\section{Effect of Stress}

The chief feature of temperature gradient diffusion that has emerged during the past year is the possibility that the movement of hydrogen in a mechanical stress gradient makes a large contribution to the phenomenon. Figure 4 shows calculated curves of the radial, tangential, and longitudinal stresses to be expected in a cylindrical specimen, similar to those used in a present work, under a temperature gradient of $110^{\circ} \mathrm{C} / \mathrm{cm}$, which is within the experimental range available. Also shown in Fig. 4 are curves of maximum shear stress and of the yield stress in shear. The former curve was derived by calculating the largest of the three shear stresses which result when the three principal stresses interact, at each radius. The yield stress was determined as a function of radius by estimating the yield stress for $0.2 \%$ offset in torsion at various temperatures and by using the calculated temperature-radius relationship for a cylinder. Note that if the maximum shear theory of strength is applicable, no plastic deformation (other than creep) should occur in a specimen 
under these conditions, since the maximum shear is everywhere less than the yield point. Therefore, the stress-strain relationships should be those applicable in elastic solids. It may be noted in passing that for a typical PWR Core 1 cladding under a temperature difference of about $300^{\circ} \mathrm{F}$, tangential stress differences of up to 20,000 psi may develop, compressive in the interior and . tensile outside.

Gibbs (Ref 6) and Rice (Ref 7) have discussed the thermodynamics of elastic deformable solids. The material is lengthy and difficult, but is essentially an extension of the laws of thermodynamics to the case where the dilation, $d v$, is not a scalar but a tensor related to the nine strain coefficients of the elastic solid, and the hydrostatic pressure likewise becomes the stress tensor. These questions are not considered by DeGroot (Ref 9) in his work in nonequilibrium thermodynamics; in fact, he explicitly regards the pressure as purely hydrostatic. There are thus independent treatments of the thermodynamics of elastic solids and the flow of matter in a temperature gradient under uniform hydrostatic pressure, but no synthesis.

Acceptance of the importance of stress gradient diffusion as contributory to thermal gradient diffusion is predicated on some knowledge of the magnitude of redistribution under isothermal stress: gradients. At present this knowledge is fragmentary. The data presented in the previous section show a very definite redistribution at $550^{\circ} \mathrm{C}$ under a comparatively light tensile load and little or no redistribution at $360^{\circ} \mathrm{C}$ under either a larger tensile load or in a cylindrical specimen with a mixed load. On the other hand, a definite redistribution was observed at $360^{\circ} \mathrm{C}$ under a light compressive load. In the specimen at $550^{\circ} \mathrm{C}$, definite plastic deformation occurred, while permanent set was either absent or very small in the lower temperature specimens. Further experiments of all three sorts are required before a quantitative understanding of how stress gradients effect hydrogen transport is achieved, and of how such gradients influence thermal diffusion. In particular, since stress gradient diffusion occurs independently whether the stress is compressional or tensile, it is not clear at present how the movement of hydrogen should be affected when both kinds of stress occur orthogonally in the same specimens.

The influence of such orthogonal stresses on hydrogen movement must be very complex. In general, Fig. 4 shows that near the axis of a specimen in a thermal gradient an element of metal undergoes a large extending stress in the tangential and longitudinal directions, and near the outside, a moderate compressive stress in the same directions. At intermediate points moderate extending stresses occur in all three directions, radial, tangential, and longitudinal. Depending on the temperature gradient and the magnitude of the temperatures, these stresses may be different in magnitude from point to point from those shown, giving rise to a shear stress curve of a much different character. Computation of the maximum shear stress is the simplest way of combining principal stresses, and such curves may turn out to be the most effective means of correlating hydrogen movement. If stress gradient diffusion makes a substantial contribution to the total thermal gradient diffusion, it is apparent that the variation of elastic properties with temperature will determine, in a complex manner, the amount of redistribution which occurs, and therefore, the value of the experimentally measured $12 \%$. 'The reproducibility of the experimental determination of the latter could not be expected to be very good unless the temperatures were made exactly the same in all experiments, and probably the mechanical history of the specimen as well.

Thus far the temperature gradient between any two specimens has not been accurately reproduced, principally because of the difficulty of making exactly equivalent thermal contact between the inside of the Zircaloy specimens and the axial cooling water. For the reasons cited above, the reproduction of $Q^{*}$ under exactly similar experimental conditions would be desirable. On the other hand, under a theoretical development which takes the stress gradient fully into account, the heat of transport, as presently derived, might fail to have any fundamental significance and might be 
replaced by some other function, otherwise determined. Therefore, for the time being, further direct thermal diffusion measurements should be deferred, especially since a reasonably representative value is available for engineering calculations.

Activity Gradient in the $\alpha-\delta$ Region

There is some relationship between the matter of stress gradient diffusion and the question of whether an activity gradient exists in the two-phase $\alpha-\delta$ region of the phase diagram. From the point of view of classical thermodynamics, the activity should be constant within this region at any temperature. In the case of zirconium hydride precipitate, however, at least two effects may operate to change the activity as the amount of precipitate increases. Considering a single aggregate of hydride molecules, those nearest the center conform to the hydride crystal habit while those nearest the surface are in a mixed crystal symmetry, influenced by the $\alpha$-matrix habit; thus surface forces arise which may add to or withdraw energy from the local matrix. Secondly, the difference in density between zirconium, $6.4 \mathrm{~g} / \mathrm{cc}$, and $\mathrm{Zr}_{2} \mathrm{H}_{3}, 5.5 \mathrm{~g} / \mathrm{cc}$, may introduce a local strain into the matrix. A rough calculation indicates an order of magnitude for the latter effect of $30 \mathrm{cal} / \mathrm{mole}$ for a change of composition from 200 to $500 \mathrm{ppm}$ at $360^{\circ} \mathrm{C}$.

Literature data on the $\alpha-\delta$ region are not very precise at low concentrations and some of the data on partial pressure differ by an order of magnitude. To the writer's knowledge, no one has carefully studied hydrogen isotherms over Zircaloy at temperatures and pressures corresponding to this range, but have extrapolated data from the $\alpha$ or $\delta$ sides through the region. Since, as has been remarked, such data tend to be contradictory, nothing in the literature can be held to disprove the possibility that activity gradients exist. Furthermore, anomalous "knees" have been observed on experimental hydrogen isotherms, which well may originate in activity gradient effects.

The direction of the increase in activity is a matter of conjecture. There are two pieces of evidence which indicate that the activity should be greatest at the $\alpha$ boundary, decreasing for higher concentrations. It has been shown experimentally that stress gradients produce movement of hydrogen to the point of highest stress. This is compatible with the present case, since lattice deformation in the zirconium matrix should occur progressively as the amount of precipitate increases. Secondly, the experiments in which a specimen of hydrogen-free Zircaloy -2 was allowed to equilibrate with a two-phase specimen, will, if substantiated, be evidence for an activity gradient in this direction. There are only two possible explanations for the failure of an originally hydrogen-free specimen to come to equilibrium at about 100-140 ppm (phase boundary at $360^{\circ} \mathrm{C}$ ) with a bulky two-phase specimen at the same temperature if the experimental data are indeed valid: Either the phase boundary is much further to the low concentration side at $360^{\circ} \mathrm{C}$ than has been suspected, which is doubtful, or the activity is not constant in the two-phase region, decreasing as the concentration increases.

The way in which the latter phenomenon could explain the data can be seen by examining the inset drawings (p. 8), which represent the hydrogen isobars (dashed lines) on the phase diagram for each of the three possible cases of activity gradient. The pressures represented by such isobars are higher the greater the temperature. Since the activity in the $\alpha$-matrix corresponds to the square root of the pressure (Sievert's Law) the isobars are also lines of constant activity. I represents the classical case of constant activity; in II the activity is higher at high concentrations for a given temperature, and III represents the case, comparable to the one under discussion, in which at a given temperature the activity is lower at greater concentrations. One can see how two specimens, at widely different concentrations, represented by the asterisks, can find themselves in equilibrium under isothermal conditions, even if one of them is in the single-phase region; specimen a, starting from zero concentration, absorbs hydrogen only until it reaches the same isobar which 

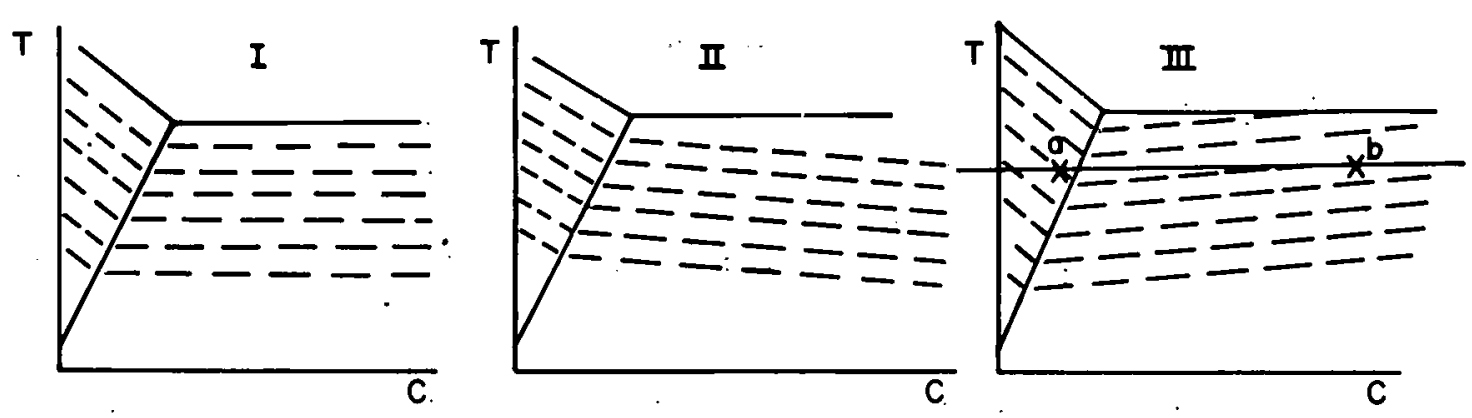

passes through the two-phase specimen b. Note that if case II were applicable, the hydrogen-free specimen and the two-phase specimen should ultimately come to exactly the same concentration, since they would not reach a common isobar until that occurred. In general, these arguments can correspond only to low or moderate two-phase concentrations, since at some point $\alpha$-phase predominates and replaces zirconium as the matrix.

The implications of activity gradients described by I, II, and III for ordinary metallurgical considerations can be assessed as follows: Consider a specimen of Zircaloy- 2 in which a linearly nonuniform concentration exists at a temperature such that all points of the specimen are within the two-phase region. Such a specimen can be represented by a horizontal line on I, II, or III with the end-points fixed by the low-and high-side specimen concentrations. In case $I$, the activity is constant at any temperature; consequently, there would be no tendency for any redistribution to occur. Some precipitation or dissolution of the hydride might occur in various parts of the specimen until the lever rule is satisfied point by point, but no movement of hydrogen in the matrix could be expected.

In case II, points closer to the boundary would be at lower activity. Hydrogen should then move in the matrix to increase the concentration of points on the low concentration side, with a corresponding concentration decrease on the high side; the process would continue until complete homogenization occurred. The original horizontal line on the diagram would shrink to a nnint, representing the average concentration. A steady state could not occur at some intermediate distribution because any excess of hydrogen in the matrix causes precipitation. The matrix concentration is fixed by the temperature; but by hypothesis any difference in overall concentration would require a difference in activity to exist.

In case III, points close to the $\alpha$ boundary, those in which the overall concentration is lower, have a higher matrix activity. Therefore, diffusion should occur in the matrix toward the higher concentration side making matrix elements close to the $\alpha$ boundary leaner in hydrogen, with resulting dissolution of precipitate. Elements on the other end of the specimen would become richer in hydrogen. Thus the original horizontal line representing the specimen on the diagram would lengthen; the process could be considered as a further unmixing. The extent of the unmixing would be determined by the nature of the activity gradient at higher concentration levels. If the activity lines shown in III were to become horizontal at higher concentrations, the concentration at which this occurred would represent the limit of the unmixing process. The final result would be one portion of the specimen, the bulk of it, at a composition corresponding to the $\alpha$ boundry and the rest of the specimen at a concentration toward the hydride side, or pure hydride. 
These considerations are, of course, highly speculative, and may be thermodynamically unsound, especially, in the writer's opinion, the argument for case III, in which diffusion leads to an increase rather than a reduction of the concentration gradient.

Kinetics

In planning the time and temperature at which any of the experiments on thermal, mechanical stress or activity gradient diffusion are to be conducted, the question of the rate of the process arises. In general, if an originally uniform specimen is placed in a thermal or mechanical stress gradient, at time zero a diffusion flow will begin, presumably influenced by the magnitude of the thermal or stress gradient and the temperature. In response to the concentration buildup thus formed, a reverse flow will be initiated, influenced by concentration gradient and the temperature. The latter process is ordinary diffusion, for which coefficients are available and for which rates can be calculated at various temperatures for various geometries. The former process is not subject to such calculation, and its kinetics are largely unknown. However, since both processes are diffusional in character, it is probable that both are influenced by thermal fluctuation phenomena in the lattice. Such phenomena depend on both a probability factor, independent of temperature, and an energetic factor, strongly temperature dependent. It is reasonable that this latter, or activation, factor is the same or similar for both processes. If this is so, then it follows that the ratio of the rates of gradient diffusion processes at any two temperatures should be the same as the ratio of rates of ordinary diffusion processes at the same temperatures. Considering the ratio of rates of diffusion processes at $700^{\circ}$ and $800^{\circ} \mathrm{K}$, which is the experimental range of interest, it turns out that the higher temperature rate is about double the lower temperature rate if the times are equal. In general

$$
R=\frac{2 t_{h}}{t_{e}}
$$

where $R$ is the rate ratio, and $t_{h}$ and $t_{e}$ are the times at higher and lower temperature, respectively. For experimental planning purposes, the equation above will be useful as a rule of thumb.

In addition to this, it is possible to calculate the length of time a given specimen, possessing initially a given distribution, would take to homogenize. Consider a cylinder, $4 \mathrm{~cm}$ in length, with all walls presumed to be insulated completely against flow of hydrogen (as discussed below, lack of insulation would create a second redistribution mechanism and would tend to decrease the time required for homogenization). Let the initial distribution be given by a function (x/4) 30 , where $x$ is a variable length, so that at one end the concentration is zero, and at the other end, $30 \mathrm{ppm}$. It can be shown that, at a temperature of $360^{\circ} \mathrm{C}$, the end concentrations would be 10 and 20 ppm after one week and 14 and $16 \mathrm{ppm}$ after two weeks. In three weeks, homogenization would be essentially complete. These conditions correspond closely to those under which, for example, the compressional stress gradient specimen 2-CG was annealed while loaded. Thus, it is seen that the existence of a gradient of $30 \mathrm{ppm}$ after three weeks at temperature is ordinarily so highly improbable as to make stress gradient diffusion the only conceivable mechanism by which such a concentration gradient could be established. This reasoning can be applied to the cylindrical thermal diffusion specimens with even greater force, since here the concentration gradient exists across a radius of only about $2 \mathrm{~cm}$ rather than a distance of $4 \mathrm{~cm}$ as in a linear specimen.

Vapor-Phase Transport

The factor which most limits the value of the stress gradient experiments performed in linear specimens is the possibility of vapor-phase "short circuiting." Since hydrogen in the metal is in equilibrium with its vapor phase at all surface points along the gradient, it is always a possibility that hydrogen redistribution occurs, not through solid-state diffusion, but through vapor-phase 
transport. In reactor design problems, the former process is the only one of interest, since the cases of highest stress and temperature gradients occur between surfaces isolatedifrom each other, as in a fuel cladding, so that vapor-phase transport is impossible. 2 This is the reason for the primary emphasis throughout this work on cylindrical specimens, in which the possibility of vaporphase transport is substantially reduced, if not eliminated.

Actually, there should be a difference in the effect of vapor-phase transport, depending on whether the process under consideration is proceeding to an equilibrium state or to a steady state. In the case of thermal diffusion the final state is, of course, a steady state, i.e., a balance of two. continuous nonequilibrium processes, as described earlier. In this case, vapor-phase transport would parallel solid-state transport by ordinary diffusion, in opposition to the thermal gradient transport. The total flux, which vanishes at steady state, would be then expressed by

$$
J=O=D\left(\frac{\partial c}{\partial x}\right)+K\left(\frac{\partial p}{\partial x}\right)-D^{1} C\left(\frac{\partial T}{\partial x}\right)
$$

where $\mathrm{k}$ is a constant related to the rate of equilibration of hydrogen gas with dissolved hydrogen, $\mathrm{C}$ is the concentration, $\mathrm{D}^{1}$ is a thermal diffusion constant, and $\mathrm{p}$ is the vapor pressure at a given point. In the absence of vapor-phase transport, the second term is zero. Thus, the presence or absence of vapor-phase transport would have a relatively strong effect on the magnitude of the concentration gradient at steady state.

However, if the process is proceeding to an equilibrium state rather than to a steady state, not only must the total flux vanish but the individual fluxes must vanish also. Therefore, the presence or absence of vapor-phase transport would be irrelevant; the final state would be the same. It is quite likely that stress gradient diffusion for perfectly elastic bodies falls into this category, since unlike the case for thermal diffusion, no irreversible energy flow is occuring during the process, which therefore resembles classical thermodynamic equilibration. However, if creep is important to the process of stress gradient diffusion, a constant flow of energy does exist and vapor-phase transport will alter the steady state, as in the case of thermal diffusion.

\section{Thermal Conductivity}

Oriani* has observed that since a steady state is characterized by a minimum entropy production consistent with imposed constraints, and since the only entropy production in thermal diffusion arises from the flow of heat, the composition ought to adjust itself in order to minimize the heat flux. Thus, in principle it ought to be possible to predict the magnitude and sign of the heat of transport from a detailed knowledge of the thermal conductivity as a function of temperature and concentration. One would assign definite conductivities to various parts of an idealized speci men by trial, adjusting the temperature-concentration relationships to conform to the known diffusion behavior of hydrogen in Zircaloy-2 (this constitutes the "sonstraint" mentioned above).

Measurements of thermal conductivity are proposed in the following section; since direct measurements are not very accurate, they will be made by measuring electrical conductivity and using the Wiedemann-Franz ratio.

\section{FUTURE WORK}

On the basis of the foregoing discussion, the following experiments will be incorporated into the program (See Appendix):

1) A series of experiments on the effects of tensile stress gradients on hydrogen movement to determine the effects of total load (both in elastic and plastic deformation regions),

\footnotetext{
* R. A. Oriani, General Electric Research Laboratory, Schenectady, N.Y., unpublished work.
} 
gradient magnitude, and temperature. Specimens have been fabricated for this study, and hydrogen has been dissolved in the first group.

2) A similar series of experiments under compressional stress gradients. Specimens are likewise ready for the initiation of this series. The maximum load is limited in this case by the physical dimensions of the apparatus.

3) A second experiment in which sections cut from a thermal diffusion specimen in which redistribution has occurred in the two-phase region are annealed isothermally. Specimen 9 (see Table I) is now undergoing a thermal gradient anneal, and sections from it will be available soon.

4) A continuation of the second activity gradient experiment (two-phase plus hydrogen-free specimen) on a larger scale, using the modified procedure described earlier.

5) A continuation of the experiments on the movement of hydrogen in an isothermal cylindrical stress gradient, in which the differential expansion method of exerting an internal pressure is replaced by a static-fluid-pressure method. Design details for these experiments have not yet been worked out.

6) Indirect measurement of the thermal conductivity of $\alpha$-Zircaloy-2 as a function of temperature and concentration. Electrical conductivity measurements will be made on Zircaloy-z wires and converted to thermal conductivity by the use of the Wiedemann-Franz ratio.

\section{REFERENCES}

1. J. M. Markowitz, "Hydrogen Redistribution in Thin Plates of Zircaloy-2 Under Large Thermal Gradients, "WAPD-TM-104, January, 1.958.

2. J. M. Markowitz, "The Thermal Diffusion of Hydrogen in Zircaloy-2, " paper No. 709, Second International Conference on the Peaceful Uses of Atomic Energy, United Nations, Geneva, June, 1958.

3. L. S. Rubenstein, "Properties of Zircaloy-2," WAPD-T-851, September, 1958. (The data used are from this report. The equation was derived by the present writer.)

4. B. Lustman and F. Kerze, ed., The Metallurgy of Zirconium, McGraw Hill, New York (1.955).

5. M. W. Mallett and W. M. Albrecht, J. Electrochem. Soc., 104, 142 (1957).

6. J. W. Gibbs, "Collected Works, "Vol. I., Yale University Press, New Haven (1957), pp. $184-218$.

7. James Rice, "The Thermodynamics of Strained Elastic Solids, "from Commentary on the Scientific Writings of J. Willard Gibbs, ' Vol. I., ed. by F. G. Donnan and Arthur Hass, Yale University Press, New Haven (1936), pp. 395-504.

8. J. Frenkel, The Kinetic Theory of Liquids, Oxford University Press, London (1946), pp. $10-11$.

9. S. R. DeGroot, Thermodynamics of Irreversible Processes, Interscience, New York (1952). 
TABLE I

THERMAL DIFFUSION EXPERIMENTS

\begin{tabular}{|c|c|c|c|c|c|c|c|c|c|c|c|}
\hline $\begin{array}{l}\text { Spjec } \\
\text { No. }\end{array}$ & $\begin{array}{c}\text { Duration } \\
\text { of run } \\
\mathrm{hr} \\
\end{array}$ & $\frac{\text { Tem }}{\text { High }}$ & Low & $\frac{e,{ }^{\circ} \mathrm{C}}{\text { Mean }}$ & ${ }^{\mathrm{T}} \mathrm{C}$ & $\begin{array}{l}\text { Gradient } \\
{ }^{\circ} \mathrm{C} / \mathrm{cm} \\
\end{array}$ & $\begin{array}{l}\text { Initial } \\
\text { conc } \\
\text { ppm }\end{array}$ & $\begin{array}{c}\text { Final } \\
\text { conc grad } \\
\text { ppm/cm }\end{array}$ & $\mathrm{kcal} / \mathrm{mo}$ & & $\begin{array}{l}+\cdots \\
\because-\text { Notes }\end{array}$ \\
\hline 1 & -- & -- & -- & -- & -- & -- & -- & $\therefore$ &.- & $\Rightarrow$ & Run failed \\
\hline 2 & 123 & 518 & 355 & 436 & 163 & 73 & 235 & 50 & -- & $\ldots$ & $\quad \quad \therefore$ \\
\hline 3 & 138 & 603 & 348 & 476 & 255 & 115 & 60 & 50 & 3.5 & $\therefore$ & $\because$ \\
\hline 4 & 138 & 622 & 310 & 466 & 312 & 114 & 60 & 30 & 2.4 & & \\
\hline 5 & 275 & 490 & 340 & 415 & 150 & 67 & 60 & 10 & 1.6 & $\therefore$ & $\cdot$ \\
\hline 6 & 410 & 484 & 384 & 434 & 100 & 45 & 30 & -- & -- & . & To be analyzed \\
\hline 7 & 430 & 338 & 138 & 238 & 200 & 93 & 60 & 55 & 6.5 & & \\
\hline 8 & -- & -- & -- & -- & -- & -- & $59 \pm 1$ & -- & $==$ & . & $\begin{array}{l}\text { Usod as ana- } \\
\text { lyticid slatidaldu }\end{array}$ \\
\hline 9 & $720 *$ & 450 & 295 & 373 & 155 & 73 & 300 & -- & -- & & $\begin{array}{l}\text { Long-term } \\
\text { annealing-in } \\
\text { progress }\end{array}$ \\
\hline 10 & -- & -- & -- & -- & -- & -- & 60 & -- & $\because$ & & $\begin{array}{l}\text { Dowtherm in-t: } \\
\text { ternal contact- } \\
\text { unsuccessful }\end{array}$ \\
\hline
\end{tabular}

* Flanited

TABLE ॥

STRESS GRADIENT DIFFUSION FXPFRIMENTS

\begin{tabular}{|c|c|c|c|c|c|c|c|c|c|c|}
\hline $\begin{array}{l}\text { Spec } \\
\text { Desig }\end{array}$ & $\begin{array}{c}\text { Type of } \\
\text { Grad }\end{array}$ & $\begin{array}{c}\text { Temp } \\
{ }^{\circ} \mathrm{C} \\
\end{array}$ & $\begin{array}{c}\text { Time } \\
\mathrm{hr} \\
\end{array}$ & $\begin{array}{l}\text { Stress } \\
\text { Low }\end{array}$ & $\frac{\text { s, psi }}{\underline{\text { High }}}$ & $\begin{array}{c}\text { Etress } \\
\text { grad } \\
\text { psi/cm } \\
\end{array}$ & $\begin{array}{c}\text { Iirilial } \\
\text { conc } \\
\text { ppm } \\
\end{array}$ & $\begin{array}{c}\text { Cunle } \\
\text { grad } \\
\mathrm{ppm} / \mathrm{cm} \\
\end{array}$ & $\begin{array}{c}\text { Permanent } \\
\text { set } \\
\text { in./in. G.L. } \\
(\%)\end{array}$ & Notes \\
\hline $1-T G$ & Tensile & 550 & 336 & 1420 & 6200 & 1670 & -- & 6 & 12 & \\
\hline $3-T G$ & Tensile & 345 & 336 & 3780 & 16500 & 3580 & 80 & 0 & -- & \\
\hline $5-T G$ & Tensile & 400 & $336 *$ & 1500 & 6000 & 1580 & -- & -- & -- & In progress \\
\hline $1-C G$ & $\begin{array}{l}\text { Compres- } \\
\text { sive }\end{array}$ & 362 & 24 & 1580 & 7750 & 1670 & 70 & -- & - & $\begin{array}{l}\text { Failed by } \\
\text { buckling }\end{array}$ \\
\hline $2-\mathrm{CG}$ & $\begin{array}{l}\text { Compres } . \\
\text { sive }\end{array}$ & 362 & 600 & 1.580 & 7750 & 1710 & $-\cdots$ & " & 1 & \\
\hline $5-C G$ & $\begin{array}{l}\text { Compres- } \\
\text { sive }\end{array}$ & 400 & $336 *$ & 1580 & 7750 & 1710 & 70 & -- & -- & In progress \\
\hline $11(\mathrm{~S})$ & Composite & 350 & 330 & $2000 t$ & $8500 \dagger$ & $4000 *$ & 60 & 0 & -- & $\begin{array}{l}\text { To be reana- } \\
\text { lyzed }\end{array}$ \\
\hline
\end{tabular}

* Planned

$\dagger$ Calculated shear stress 


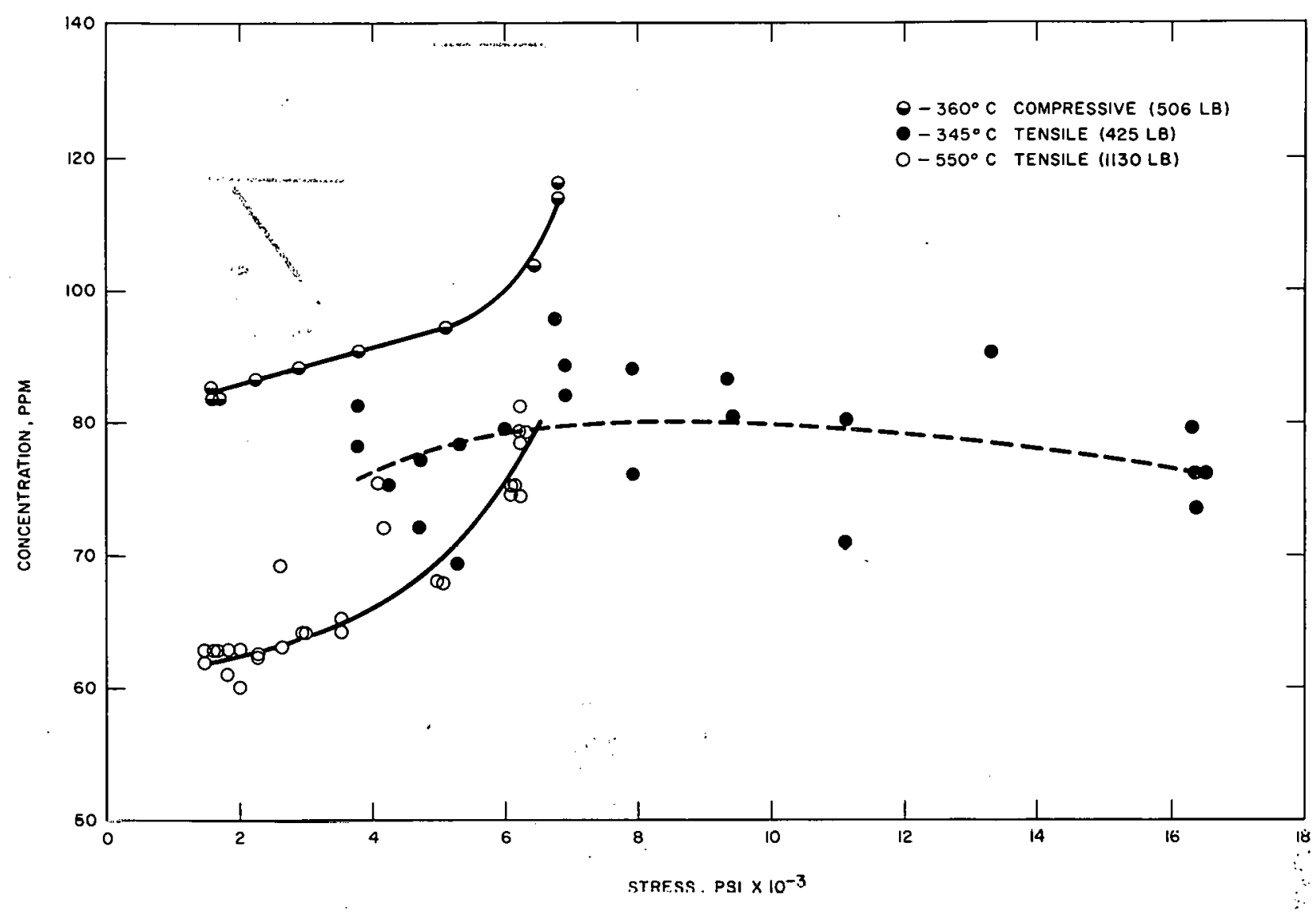

"Fig. I Stress Gradient Diffusion

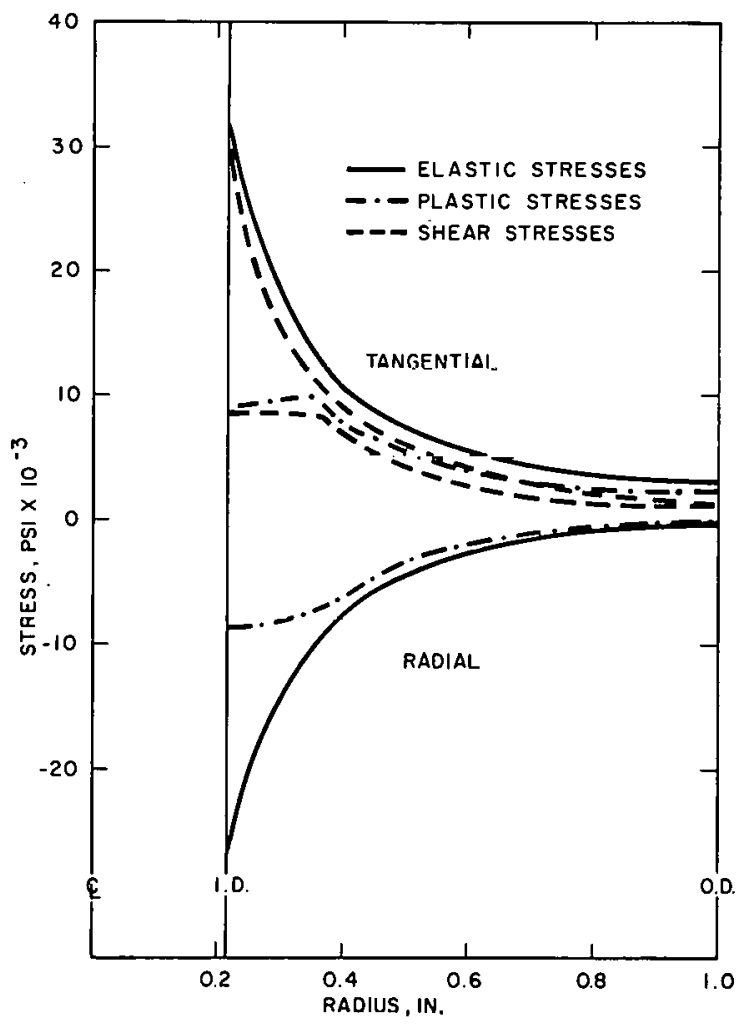

Fig. 2 Stresses in Annulus (Zircaloy-2 with Stainless Steel Axial Plugl 


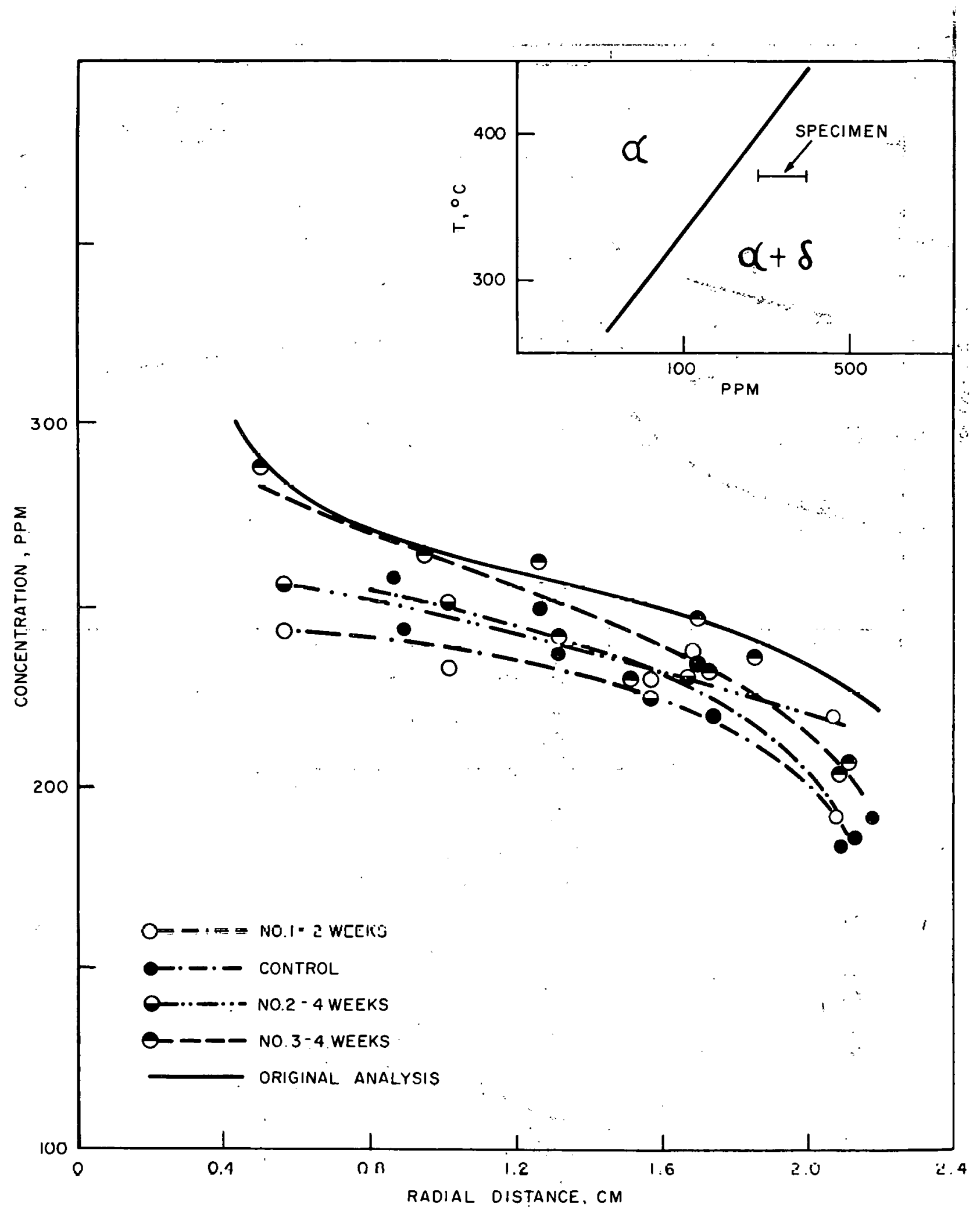

Fig. 3 Hedge Snecimens 


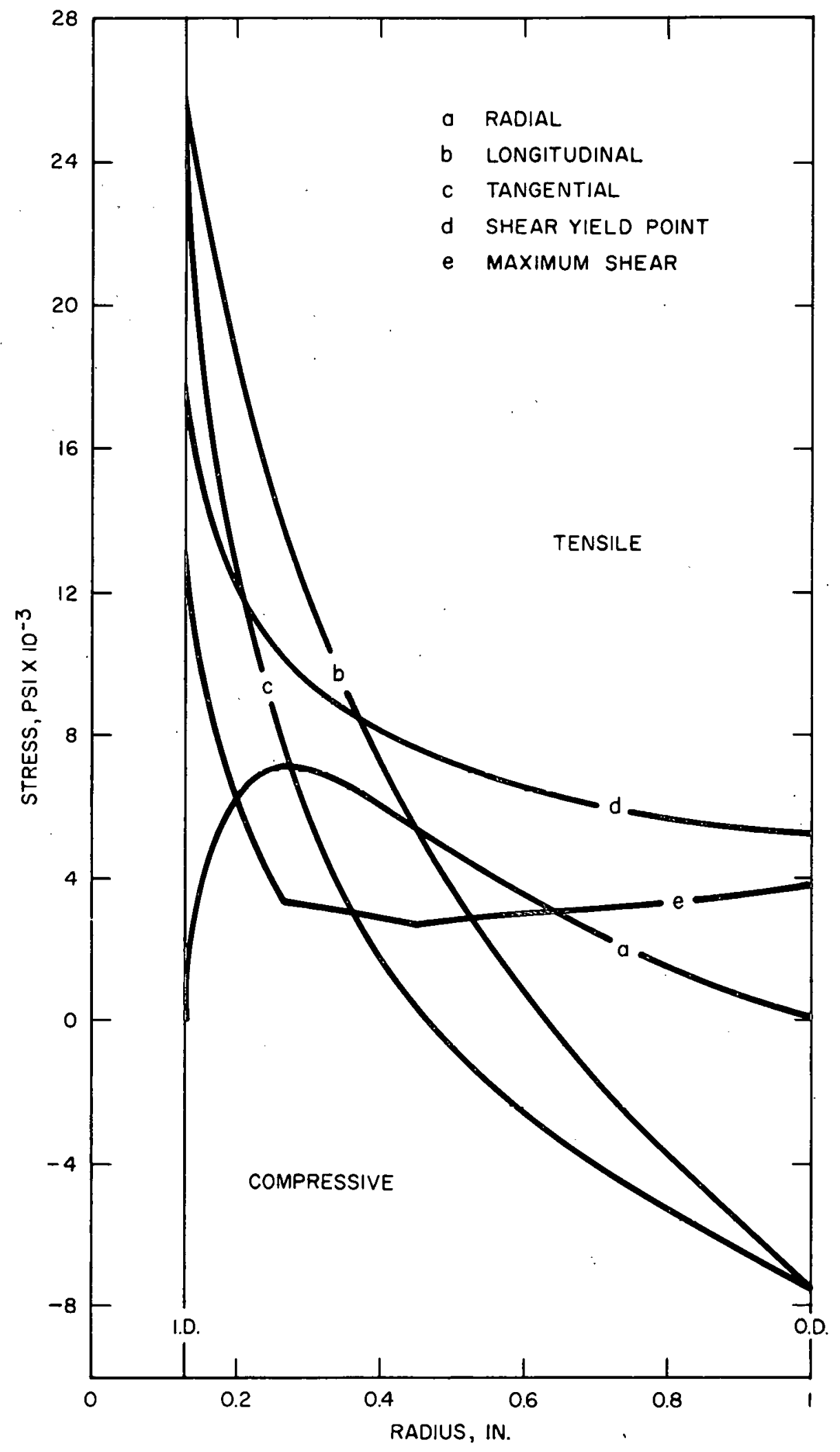

Fia. 4 Thermal Stresses in a Cylinder 


\section{APPENDIX I: Experimental Program}

1.. Tensile Stress Gradient Experiments

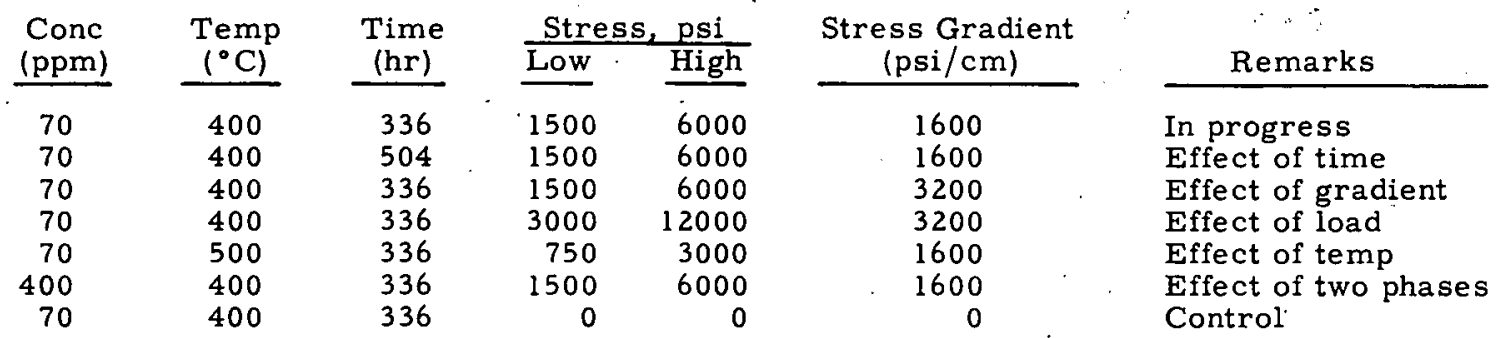

2. Compressive stress gradient experiments

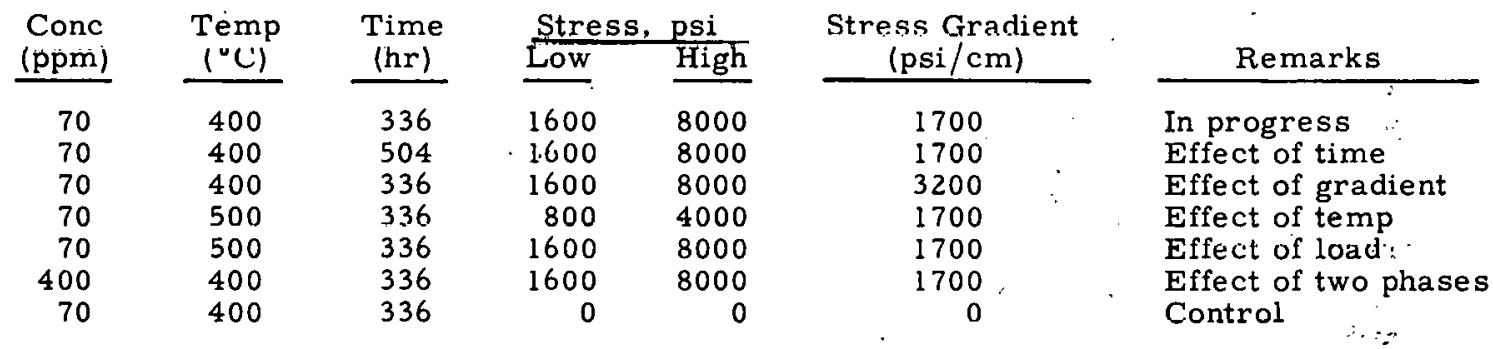

3. Composite cylindrical stress gradient experiments

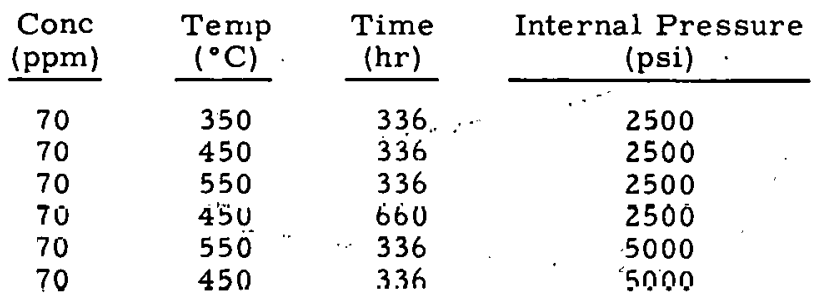

Expected

\begin{tabular}{l} 
Specimen Cond \\
\hline fully elastic \\
fully elastic \\
partly elastic \\
fully elastic \\
mostly elastic \\
fully claotic
\end{tabular}

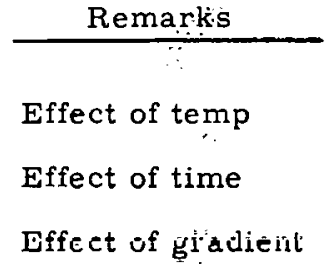

4. Activity gradient experiments

a. Two-phase, single-phase specimens

Conc Lg Piece, ppm

1000
1000
1000
1000
1000
500
500
500
500
300
300
300
200
200
100

Annealing Temp, ${ }^{\circ} \mathrm{C}$

300
350
400
450
500
300
350
400
450
300
350
400
300
350
300


b. Two-phase, two-phase specimens

\begin{tabular}{cccc} 
Conc, ppm & Conc, ppm & Annealing temp, ${ }^{\circ} \mathrm{C}$ & Time, weeks \\
\cline { 2 - 3 } 2000 & 1000 & 500 & 2 \\
1000 & 300 & 400 & 2 \\
1000 & 300 & 400 & 4 \\
1000 & 300 & 300 & 4 \\
500 & 200 & 300 & 4
\end{tabular}

5. Thermal conductivity measurements

Measurements will be made at $50^{\circ} \mathrm{C}$ temperature intervals on Zircaloy-2 wires containing from 30 to $100 \mathrm{ppm}$ hydrogen. 